\title{
Transient Neonatal Diabetes Mellitus in Sibs
}

\author{
ARTHUR W. FERGUSON and R. D. G. MILNER \\ From the Luton and Dunstable Hospital and Bedford General Hospital, and the Department of \\ Biochemistry, University of Cambridge
}

\begin{abstract}
Ferguson, A. W., and Milner, R. D. G. (1970), Archives of Disease in Childhood, 45, 80. Transient neonatal diabetes mellitus in sibs. The occurrence of transient neonatal diabetes mellitus in successive male sibs is described. Both infants were small in relation to their periods of gestation and the placentas were abnormal. Subsequent investigation of the mother revealed a flat glucose tolerance curve with normal plasma insulin levels. Transient neonatal diabetes mellitus may be due to delayed maturation of fetal $\beta$-cells caused by a combination of maternal and placental factors.
\end{abstract}

The clinical syndrome described as 'transient neonatal diabetes mellitus' or 'idiopathic neonatal hyperglycaemia' has become more widely known since Hutchison and his colleagues (1962) described 4 cases and reviewed 8 which had been recorded previously. Since then further case reports have occurred sporadically. The pathological basis of the condition remains obscure, though a prominent feature is that affected infants are usually small for their gestational age.

Two cases are presented here because the condition has not previously been reported in sibs.

\section{Case Histories}

These brothers were the first and second-born children of healthy, unrelated parents. Both infants developed all the features of transient neonatal diabetes mellitus. The diagnosis was made much earlier in the second infant because the condition was anticipated. Both infants were small in relation to the period of gestation and in both cases the placenta was small and infarcted.

Case 1. This male infant was born on 14 November 1963 at 42 weeks gestation, birthweight $2155 \mathrm{~g}$. The mother, aged 21 years, had a normal pregnancy with no toxaemia, and labour was induced surgically because of fetal postmaturity. During the second stage there was meconium-stained liquor and slowing of the fetal heart during uterine contractions. After an episiotomy the infant was born by spontaneous vertex delivery. He was limp and blue but cried immediately. Regular respirations were established at 5 minutes. The placenta was grossly infarcted and calcified, but was not weighed.

Received 21 May 1969.
The infant was breast-fed and sucked well. However? he failed to gain weight, and on the 15th day begap to vomit occasionally. On the 19th day he was tran\& ferred to the Children's Ward for further investigatiog $\mathrm{He}$ then weighed $2065 \mathrm{~g}$., was marasmic, wide-eye and thirsty, with a rectal temperature of 39.4 (Fig.). Blood sugar, $720 \mathrm{mg} . / 100 \mathrm{ml}$; CSF suga $\overrightarrow{6}$ $405 \mathrm{mg}$./100 ml.; CSF protein, chloride, and cell cợni

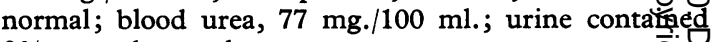
$2 \%$ sugar but no ketones.

A subcutaneous infusion of $1 / 5$ normal saline ?w. given. All urine voided was collected and tested fe्f sugar and acetone. Soluble insulin was given two three times daily in doses ranging from 2 to 6 units.

Ketones were never found in the urine. Adminis stered insulin totalled 12 units daily for most of the first fortnight, but thereafter the dose gradually fell. No attempt was made to keep the urine entirely suga? free because of the particular dangers of hypoglycaemia in infancy. However, at 5 weeks a brief hypoglycaemac convulsion occurred which was terminated by introf venous glucose. From the start of treatment there was immediate clinical improvement and a steady gain weight.

At 6 weeks intermittent vomiting, abdominal diste⿳sion, fever, and diarrhoea developed, associated of three occasions (2, 3, and 6 January 1964) with serum potassium over $7 \mathrm{mEq} / \mathrm{l}$., and with low sodium and chloride levels. On these dates blood sugar levews of 550,770 , and $60 \mathrm{mg} . / 100 \mathrm{ml}$. were recorded. The 24-hour urinary 17-oxosteroid and total oxogenid steroid excretion (5-6 January) were $0 \cdot 15$ and $0.64 \mathrm{mg}$ respectively. Blood urea was $30 \mathrm{mg} . / 100 \mathrm{ml}$. and blood culture was negative. There was a tachycardiga of 200/min., and the systolic blood pressure in the arm by the flush technique was $75 \mathrm{~mm}$. $\mathrm{Hg}$. Adren? insufficiency was suspected and desoxycorticostero acetate $1 \mathrm{mg}$. daily and subcutaneous $1 / 5$ normal saline were administered from 7-10 January. Rapid clinic 


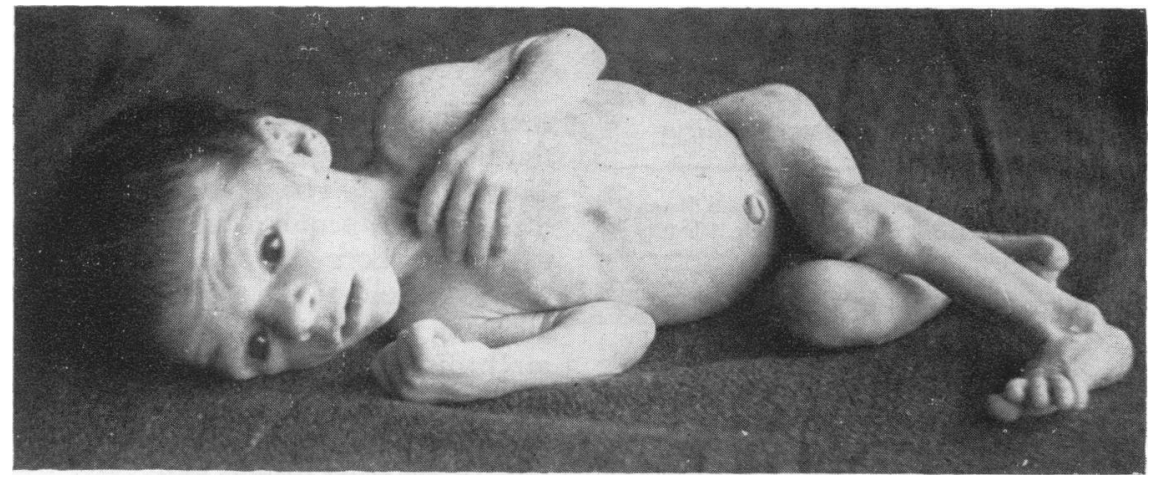

FIG.-Case 1 aged 19 days when neonatal diabetes mellitus was diagnosed.

and biochemical recovery occurred and there was no subsequent similar relapse.

By 15 weeks when he was discharged weighing $4 \cdot 25$ kg. his insulin requirements had stabilized at $2 \mathrm{U} /$ day, and 2 days later insulin was discontinued entirely. During the first 3 weeks at home, sugar was found in the urine in only 3 out of 105 tests. Three random blood. sugar measurements in the fourth and fifth months were below $110 \mathrm{mg}$. $/ 100 \mathrm{ml}$. At 8 months he weighed $9 \mathrm{~kg}$. and his physical and mental development were normal. A glucose tolerance test at age 7 months gave the following blood sugar levels (mg./100 ml.): fasting 76; $30 \mathrm{~min} .$, 176; $60 \mathrm{~min} .$, 128; $90 \mathrm{~min} ., 120$; 120 min., 110; 180 min., 128. Subsequent physical and mental progress was normal, and at 2 years he weighed $13 \cdot 7 \mathrm{~kg}$.

Case 2. This male infant was born on 5 September 1965, at 40 weeks' gestation, birthweight $2360 \mathrm{~g}$. The pregnancy was uneventful, with no toxaemia or hypertension. A spontaneous vertex delivery followed an episiotomy for fetal distress and meconium-stained liquor. The infant cried immediately. The placenta was described as 'very small and gritty'. The duration of labour was: first stage, $14 \mathrm{hr}$.; second stage, $1 \mathrm{hr}$.; third stage, $10 \mathrm{~min}$.

Because his brother had had transient neonatal diabetes mellitus, daily urine sugar tests were performed. These were positive from the third day, and on the fifth day the blood sugar level was $650 \mathrm{mg} . / 100 \mathrm{ml}$. The infant was then transferred to the Children's Ward, where he was noted to be thin and pale with a dry tongue, but a vigorous cry. 8 units of soluble insulin were given intramuscularly at 3.30 p.m., and $1 / 5$ normal saline was infused intravenously. At 5 p.m. the blood sugar was $518 \mathrm{mg}$. $/ 100 \mathrm{ml}$.; serum sodium, $123 \mathrm{mEq} / 1$. ; potassium, 7.4 mEq/l.; chloride, $116 \mathrm{mEq} / 1$.; blood urea, $82 \mathrm{mg} . / 100 \mathrm{ml}$. By 10 p.m. the blood sugar had fallen to $225 \mathrm{mg}$. $/ 100 \mathrm{ml}$., and by 10 a.m. the following morning it was $49 \mathrm{mg}$. $100 \mathrm{ml}$. Whenever possible, urine sugar tests were done before each feed and 2-4 units soluble insulin were given if the urine contained $\theta^{5} 75 \%$ or more sugar. Feeds of normally reconstituted evaporated cow's milk without added sugar were taken well, and the intravenous infusion was stopped after 24 hours. Blood sugar tests at random times, daily for the first week and subsequently twice weekly, tended to be over $300 \mathrm{mg} . / 100 \mathrm{ml}$. The usual daily total of administered soluble insulin was 8 units during the first month of treatment. A hypoglycaemic episode with convulsive movements and a negative 'Dextrostix' test on capillary blood occurred at 8 weeks, but was terminated by $5 \mathrm{ml}$. $50 \%$ glucose intravenously. Thereafter, a gradual reduction in the daily dose of insulin was possible, reaching 2 units when the baby was 12 weeks old. After the age of 14 weeks no further insulin was given and all urine tests remained negative until the baby was allowed home aged 15 weeks. $\mathrm{He}$ continued to thrive and there was no recurrence of glycosuria. At 10 months he weighed $8.6 \mathrm{~kg}$. and a glucose tolerance test gave the following blood sugar levels (mg./100 ml.) fasting, 85; $30 \mathrm{~min} ., 95 ; 60 \mathrm{~min}$., 84 ; 90 min., 75; 120 min., 73; 150 min., 74. At the age of 18 months physical and mental development was normal.

The mother was a healthy young woman of $1.75 \mathrm{~m}$. height who tended to be plump. In neither pregnancy did she have significant albuminuria, oedema, or hypertension. Because of the experience with her first baby, she was given a glucose tolerance test early in her second pregnancy with the following results (blood sugar, $\mathrm{mg}$. $/ 100 \mathrm{ml}$.): fasting, $80 ; 2 \mathrm{hr}$., $110 ; 3 \mathrm{hr}$., 116; $4 \mathrm{hr} ., 95 ; 5 \mathrm{hr} ., 85 ; 6 \mathrm{hr} ., 85$. After her second child also had temporary neonatal diabetes mellitus a further glucose tolerance with plasma insulin determinations (Hales and Randle, 1963) was performed 16 months after birth (see Table). No abnormality of plasma insulin in response to oral glucose was detected, but the glucose curve was 'flat'.

\section{Discussion}

There is a striking uniformity in the clinical pattern of transient neonatal diabetes mellitus. The affected infants are small for their gestational age and have a poor placenta. At the onset of the 
TABLE

Blood Sugar and Plasma Insulin Levels during Oral Glucose Tolerance Test in Mother ${ }^{\star}$ of Brothers who had Temporary Neonatal Diabetes Mellitus

\begin{tabular}{c|c|c}
\hline $\begin{array}{c}\text { Time After Oral } \\
\text { Glucose (min.) }\end{array}$ & $\begin{array}{c}\text { Plasma Insulin } \\
(\mu \mathrm{U} / \mathrm{ml} .)\end{array}$ & $\begin{array}{c}\text { Blood Sugar } \\
(\mathbf{m g} . / 100 \mathbf{m l} .)\end{array}$ \\
\hline 0 & 20 & 85 \\
30 & 111 & 95 \\
60 & 90 & $\mathbf{8 4}$ \\
90 & 26 & $\mathbf{7 5}$ \\
120 & 24 & $\mathbf{7 3}$ \\
150 & 34 & 74 \\
\hline
\end{tabular}

$\star$ The test was performed 16 months after the delivery of the mother's second child.

illness they have failed to gain weight and have hyperglycaemia with glycosuria but no ketonuria. Low doses of insulin are effective and after a time spontaneous regression of the diabetes occurs. The present cases conformed to this picture and being the first sibs to be reported with the condition, they lend emphasis to the viewpoint that some aspect of intrauterine life is important in the genesis of the diabetes.

Hypoinsulinism due to a delay in the development of the endocrine pancreas was suggested as an explanation for transient neonatal diabetes by Gerrard and Chin (1962). The concept was based on the hypothesis that fluctuations in fetal blood glucose levels are necessary for the normal functional development of the $\beta$-cell and the discovery that the mother of their case had persistently low blood glucose levels. There is good evidence in favour of the corollary: babies born to diabetic mothers, who have large fluctuations in blood sugar levels, have hypertrophy and hyperplasia of the pancreatic islets (Cardell, 1953) and hyperinsulinism (Baird and Farquhar, 1962). It may be relevant, therefore, that the mother of the present cases also had a flat glucose tolerance curve (Table).

The evidence for hypoinsulinism postnatally, however, is scanty, though the effectiveness of small doses of exogenous insulin possibly favours the concept. There is only one report ${ }^{\star}$ of a systematic study of plasma insulin levels in a baby with transient diabetes mellitus (Ferguson, 1967). In this infant intravenous tolbutamide was followed by a rise in plasma insulin and a fall in blood glucose levels, demonstrating the ability of the pancreas to release insulin and of the tissues to respond to it. There was also a rise in plasma insulin levels in response to oral glucose, but the glucose tolerance was diabetic. Those results could be interpreted as having indicated insensitivity of the

* See addendum. $\beta$-cell to glucose, but provided no evidence of insulin antagonism.

The idea that insulin antagonism, due to the? transplacental passage of antibodies, could cause $\vec{F}$ transient neonatal diabetes was put forward by Scott (1966). The suggestion rested on the fact $\frac{}{\circ}$ that passively acquired maternal antibodies persist $\frac{\bar{c}}{\bar{D}}$ in the newborn for approximately 12-16 weeks, $\overrightarrow{\mathrm{\sigma}}$ a period similar to the common duration of transient $\stackrel{\circ}{\circ}$ neonatal diabetes. Direct evidence of such a \% mechanism is lacking, however, and, furthermore, $\overrightarrow{0}$ infants of mothers with diabetes mellitus do not get temporary diabetes, though many of them $\vec{\omega}$ receive maternal insulin antibodies transplacentally (Spellacy and Goetz, 1963).

The fact that a large majority of the reported if cases are small for their gestational ages and have a $i$ poor placenta is striking. The placenta is an important source of fetal steroids and there is both 0 in vitro and in vivo evidence that steroids play a role $\circ$ in the development of the fetal endocrine pancreas.

Differentiation of the $\beta$-cells of fetal rat pancreas $\vec{\pi}$ grown in organ culture occurred only if the tissue $\mathbb{D}$ was incubated in the presence of fetal rat adrenal cortex (Zagury, 1959). Murrell (1966) cultured fetal rat pancreas in a medium containing hydro- $\vec{\varphi}$ cortisone, and found that the tissue developed aldehyde fuchsin-positive cells, granulated $\beta$-cels, but no pancreatic acini. The insulin content ơf the explanted pancreas was greater than that of tissue which had developed in utero (Murrell, Morgan, and Lazarow, 1966).

Precocious development of rabbit fetal exocrine $\stackrel{\square}{\stackrel{\circ}{\circ}}$ and endocrine pancreas was noted when cortisone $\overrightarrow{\hat{O}}$ or ACTH was administered to pregnant rabbits 3 (Lee and Ring, 1956). If steroids are necessary $\supset$ for the normal development of the human $\beta$-cell placental insufficiency could impair insulin secretion in utero either directly or by an effect on the fetal adrenal cortex. It is of interest that Case $1 \div$ had one episode when he showed some clinical and biochemical features of adrenal hypofunction $\delta$ which responded promptly to treatment.

From the available evidence it seems likely that 웅 transient neonatal diabetes mellitus is due to $D$ delayed maturation of fetal $\beta$-cells. The delay may be caused by a combination of maternal and $\tilde{N}$ placental factors. First, a relatively non-fluctuating or maternal blood sugar level might deprive the $O$ fetal $\beta$-cell of a stimulus to development (Gerrard $\tilde{\omega}$ and Chin, 1962). Secondly, poor placental func- tion may contribute to delayed $\beta$-cell maturation 6 through a deficiency of steroid hormone production. $\mathbb{\Phi}$

With the present emphasis on the screening of $\stackrel{\infty}{+}$ small-for-dates babies to detect hypoglycaemia, $\frac{T}{0}$ 
more early cases of transient neonatal diabetes may come to light. Once diagnosed, it is desirable to investigate cases, before treatment begins, by a glucose tolerance test incorporating measurements of plasma insulin levels. When a number of infants have been so studied the roles of insulin deficiency and antagonism in the condition may become clearer.

We record our appreciation of the clinical care given by Drs. M. Von Thomann and G. Gilani, Paediatric Registrars, and of the nursing care by Sister $S$. Williams.

\section{REFERENCES}

Baird, J. D., and Farquhar, J. W. (1962). Insulin-secreting capacity in newborn infants of normal and diabetic women. Lancet, 1,71 .

Cardell, B. S. (1953). The infants of diabetic mothers: a morphological study. Fournal of Obstetrics and Gynaecology of the British Empire, 60, 834.

Ferguson, I. C. (1967). Neonatal hyperglycaemia: case report with plasma insulin studies. ibid, 42, 509.

Gerrard, J. W., and Chin, W. (1962). The syndrome of transient diabetes. Fournal of Pediatrics, 61, 89.

Hales, C. N., and Randle, P. J. (1963). Immunoassay of insulin with insulin-antibody precipitate. Biochemical fournal, 88, 137.

Hutchison, J. H., Keay, A. J., and Kerr, M. M. (1962). Congenital temporary diabetes mellitus. British Medical fournal, 2, 436.
Lee, J., and Ring, P. A. (1956). The effect of maternally administered cortisone and ACTH upon the pancreas of the foetus. Fournal of Endocrinology, 14, 284.

Murrell, L. R. (1966). Mammalian pancreatic islet tissue in organ culture. I. Methods of culture and in vitro histogenesis. Experimental Cell Research, 41, 350.

- Morgan, C. R., and Lazarow, A. (1966). Mammalian pancreatic islet tissue in organ culture. II. Insulin contents of tissues and culture medium. ibid., 41, 365.

Scott, J. S. (1966). Immunological diseases and pregnancy. British Medical fournal, 1, 1559.

Spellacy, W. N., and Goetz, F. C. (1963). Insulin antibodies in pregnancy. Lancet, 2, 222.

Zagury, D. (1959). La culture de pancréas endocrine chez le rat et l'insulogenèse. Comptes Rendus Hebdomadaires des Séances de l'Académie de Sciences, 249, 2834.

\section{Addendum}

Since this paper was submitted for publication, low pretreatment plasma insulin levels have been reported by Gentz in 2 affected infants.

\section{REFERENCE}

Gentz, J. (1969). Acta Paediatrica Scandinavica, 58, 655.

Correspondence to Dr. A. W. Ferguson, Bedford General Hospital (south wing), Kempston Road, Bedford, England. 